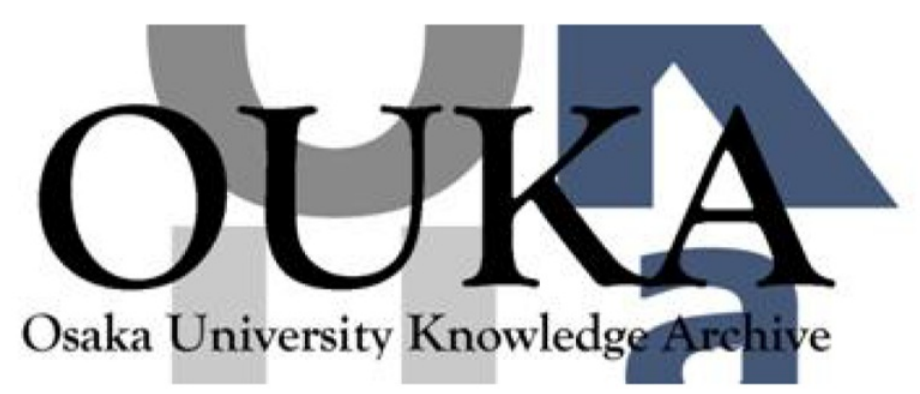

\begin{tabular}{|c|c|}
\hline Title & $\begin{array}{l}\text { Effect of rubber compounding agent on adhesion } \\
\text { strength between rubber and heat-assisted } \\
\text { plasma-treated polytetrafluoroethy lene (PTFE) }\end{array}$ \\
\hline Author(s) & $\begin{array}{l}\text { Ohkubo, Yuji; Shibahara, Masafumi; Ishihara, } \\
\text { Kento et al. }\end{array}$ \\
\hline Citation & Journal of Adhesion. 95(3) p.242-p. 257 \\
\hline Issue Date & $2018-02-14$ \\
\hline oaire:version & VoR \\
\hline URL & https://hdl. handle. net/11094/84519 \\
\hline rights & $\begin{array}{l}\text { ๑ } 2018 \text { The Author(s). Published by Taylor } \& \\
\text { Francis. This is an Open Access article. Non- } \\
\text { commercial re-use, distribution, and } \\
\text { reproduction in any medium, provided the } \\
\text { original work is properly attributed, cited, } \\
\text { and is not altered, transformed, or built upon } \\
\text { in any way, is permitted. The moral rights of } \\
\text { the named author(s) have been asserted. }\end{array}$ \\
\hline Note & \\
\hline
\end{tabular}

Osaka University Knowledge Archive : OUKA

https://ir. Library. osaka-u. ac. jp/

Osaka University 


\title{
Effect of rubber compounding agent on adhesion strength between rubber and heat-assisted plasma-treated polytetrafluoroethylene (PTFE)
}

\author{
Yuji Ohkubo, Masafumi Shibahara, Kento Ishihara, Asahiro Nagatani, Koji \\ Honda, Katsuyoshi Endo \& Kazuya Yamamura
}

To cite this article: Yuji Ohkubo, Masafumi Shibahara, Kento Ishihara, Asahiro Nagatani, Koji Honda, Katsuyoshi Endo \& Kazuya Yamamura (2019) Effect of rubber compounding agent on adhesion strength between rubber and heat-assisted plasma-treated polytetrafluoroethylene (PTFE), The Journal of Adhesion, 95:3, 242-257, DOI: 10.1080/00218464.2018.1428095

To link to this article: https://doi.org/10.1080/00218464.2018.1428095

$$
\begin{aligned}
& \text { (c) } 2018 \text { The Author(s). Published by Taylor \& } \\
& \text { Francis. }
\end{aligned}
$$

\section{Published online: 14 Feb 2018.}

Submit your article to this journal $\pi$

$$
\text { III Article views: } 466
$$

View Crossmark data $\nearrow$

Citing articles: 1 View citing articles $\asymp$ 


\title{
Effect of rubber compounding agent on adhesion strength between rubber and heat-assisted plasma-treated polytetrafluoroethylene (PTFE)
}

\author{
Yuji Ohkubo (10), Masafumi Shibaharab ${ }^{\mathrm{b}}$, Kento Ishihara ${ }^{\mathrm{a}}$, Asahiro Nagatani ${ }^{\mathrm{b}}$, \\ Koji Hondac, Katsuyoshi Endo ${ }^{a}$, and Kazuya Yamamura ${ }^{a}$

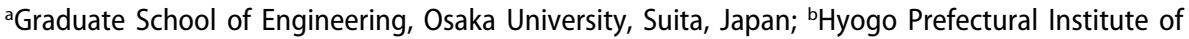 \\ Technology, Kobe, Japan; 'Technical Support Center for Leather Industries, Hyogo Prefectural Institute \\ of Technology, Hyogo, Japan
}

\begin{abstract}
Although heat-assisted plasma treatment enables drastic improvement of the adhesion property of polytetrafluoroethylene (PTFE), plasma-treated PTFE does not strongly adhere to any adherend. To clarify which rubber compounding agents positively affect the adhesion strength of a plasma-treated PTFE/rubber assembly, six types of unvulcanised rubbers were prepared and thermally compressed to a plasma-treated PTFE sheet. Thus, it was found that $\mathrm{SiO}_{2}$ addition to rubber drastically increased the adhesion strength of a plasma-treated PTFE/rubber assembly and cohesion failure of rubber occurred with large fractions of $\mathrm{SiO}_{2}$ although no adhesives were used. To confirm the reaction between plasma-treated PTFE and $\mathrm{SiO}_{2}$ powder, $\mathrm{X}$-ray photoelectron spectroscopy (XPS) measurements were performed for the thermally compressed $\mathrm{SiO}_{2} / \mathrm{PTFE}$ assembly after repeated washing. The XPS results indicated that hydrophilic $\mathrm{SiO}_{2}$ powder strongly adhered to the plasma-treated PTFE, whereas hydrophobic $\mathrm{SiO}_{2}$ powder did not adhere to the PTFE. In this paper, a model was proposed for a possible mechanism of strong adhesion of a PTFE/rubber assembly through both hydrogen and covalent bonds between silanol groups of the $\mathrm{SiO}_{2}$ powder surface in the rubber and hydroxyl or carboxyl groups on the plasma-treated PTFE.
\end{abstract}

\section{ARTICLE HISTORY}

Received 2 November 2017; Accepted 11 January 2018

\section{KEYWORDS}

Adhesive-free adhesion; fluoropolymers; rubber compounding agent; silica; surface treatment by exited gases; X-ray photoelectron spectroscopy

\section{Introduction}

Rubber has elasticity but poor chemical resistance and sliding properties. In contrast, polytetrafluoroethylene (PTFE), which is a fluoropolymer, has high chemical resistance and good sliding properties but no elasticity. Combining rubber and PTFE can compensate for the disadvantages of

CONTACT Yuji Ohkubo okubo@upst.eng.osaka-u.ac.jp @ Graduate School of Engineering, Osaka University, 2-1 Yamadaoka, Suita, Osaka 565-0871, Japan.

Y. Ohkubo, K. Endo, and K. Yamamura supervised the work. K. Ishihara and Y. Ohkubo fabricated the PTFE samples. M. Shibahara and A. Nagatani fabricated the IIR samples. M. Shibahara, K. Honda, and Y. Ohkubo performed the experiments. K. Yamamura and K. Endo give comments to the measurements. All authors contributed to the scientific discussion and the manuscript preparation. Y. Ohkubo wrote the manuscript.

Color versions of one or more of the figures in the article can be found online at www.tandfonline.com/gadh. 
both materials. However, PTFE does not easily adhere to other types of materials. PTFE not only has an extremely low surface energy, in common with fluoropolymers, but also has a weak boundary layer (WBL). ${ }^{[1,2]}$ Therefore, it is essential not only to generate oxygen-containing radicals and functional groups on PTFE surfaces but also to remove and/or recover the WBL of PTFE surface to improve its adhesion property. To generate oxygen-containing radicals and functional groups and remove and/or recover the WBL, corrosive solutions such as sodium-naphthalene and sodium-ammonium complex solutions have been used as conventional methods. ${ }^{[3,4]}$ As a result, the adhesion properties of PTFE drastically improved. However, corrosive solutions have significant disadvantages: a negative impact on humans and the environment, strong odours, and sodium residues on PTFE. An alternative method that does not require the corrosive solutions has, therefore, long been needed. Although many researchers attempted to develop an alternative method via surface treatments involving dry processes such as ion and plasma irradiation, the realisation of good adhesion properties of PTFE (over $1 \mathrm{~N} / \mathrm{mm}$ ) has been difficult. $^{[5-9]}$ Therefore, several combinations of surface treatments such as plasma irradiation and surface graft polymerisation were developed. ${ }^{[4,10-12]}$ In addition, in recent years, good adhesion properties of PTFE were realised without graft polymerisation under special conditions of ion or plasma irradiation by Yumoto's ${ }^{[13]}$ and Ohkubo's groups. ${ }^{[1,15]}$ Yumoto's group reported that the adhesion strength between ion-irradiated PTFE and polypropylene tape containing glass fibre through an epoxy adhesive drastically increased to $1.5 \mathrm{~N} / \mathrm{mm}$ upon $\mathrm{N}_{2}$ ion irradiation under a high acceleration voltage. Ohkubo's group reported that the adhesion strength between plasma-treated PTFE and isobutylene-isoprene rubber (IIR) drastically increased to over $2.0 \mathrm{~N} / \mathrm{mm}$ upon helium $(\mathrm{He})$ heat-assisted plasma treatment at above $200^{\circ} \mathrm{C}$. In the report, cohesion failure of IIR occurred in the middle of T-peel test despite the absence of adhesives and graft polymerisation agents. Although Ohkubo et al. studied a modified PTFE surface in detail by electron spin resonance (ESR) measurement, X-ray photoelectron spectroscopy (XPS), scanning electron microscopy, atomic force microscopy, nanoindentation, and contact angle measurement and achieved extremely strong adhesion between the plasma-treated PTFE and other materials, the rubber surface was barely studied. Thus, the mechanism of strong adhesion is unclear. Although there are several reports on improved adhesion strength between rubber and metal without using adhesives ${ }^{[16-19]}$, there are few reports on the improvement of the adhesion strength between rubber and plasma-treated fluoropolymers. In this study, we prepared six types of rubbers to clarify which components in rubber affect the adhesion strength of a plasma-treated PTFE/rubber assembly. In addition, a direct 
adhesion test of the rubber compounding agent, which induces strong adhesion, with the plasma-treated PTFE was performed.

\section{Experimental}

\section{Materials}

Commercially available PTFE sheet (NITOFLON ${ }^{\circledR}$ No.900UL, Nitto Denko: Osaka, Osaka, Japan, thickness: $0.2 \mathrm{~mm}$ ) was cut into $35 \mathrm{~mm} \times 70 \mathrm{~mm}$ pieces, which were used as fluoropolymer specimens. Six types of unvulcanised rubbers were mixed and prepared using the materials shown in Table 1-6. Sulphur-free

Table 1. Components of sample 1.

\begin{tabular}{llc}
\hline Role & \multicolumn{1}{c}{ Material } & Amount [g] \\
\hline Main component of rubber & Sulfur-free chloroprene rubber (CR) & 100 \\
Vulcanisation accelerator & $N$-(tert-Butyl)-2-benzothiazolesulfenamide (BBS) & 0.35 \\
Vulcanisation accelerator aid & Zinc oxide (ZnO) & 5 \\
Vulcanisation accelerator aid & Stearic acid & 0.5 \\
Reinforcing material & Cellulose powder & 30 \\
Plasticizer & Magnesium oxide (MgO) & 4 \\
Antioxidant for rubber & $N$-Phenyl-1-naphthylamine & 1 \\
\hline
\end{tabular}

${ }^{*}$ Vulcanisation condition of Sample 1: $180^{\circ} \mathrm{C}, 20 \mathrm{~min}$

Table 2. Components of sample 2.

\begin{tabular}{llc}
\hline Role & \multicolumn{1}{c}{ Material } & Amount [g] \\
\hline Main component of rubber & Natural rubber (NR) & 100 \\
Crosslinking agent & Dicumyl peroxide & 1.5 \\
Reinforcing material & Cellulose powder & 25 \\
\hline
\end{tabular}

*Vulcanisation condition of Sample 2: $170^{\circ} \mathrm{C}, 6.0 \mathrm{~min}$

Table 3. Components of sample 3.

\begin{tabular}{llc}
\hline Role & \multicolumn{1}{c}{ Material } & Amount [g] \\
\hline Main component of rubber & Natural rubber (NR) & 100 \\
Crosslinking agent & Sulfur fine powder & 3.5 \\
Vulcanisation accelerator & $N$-(tert-Butyl)-2-benzothiazolesulfenamide (BBS) & 0.7 \\
Vulcanisation accelerator aid & Zinc oxide (ZnO) & 6 \\
Vulcanisation accelerator aid & Stearic acid & 0.5 \\
\hline
\end{tabular}

*Vulcanisation conditions of Sample 3: $160^{\circ} \mathrm{C}, 5.0 \mathrm{~min}$

Table 4. Components of sample 4.

\begin{tabular}{llc}
\hline Role & \multicolumn{1}{c}{ Material } & Amount [g] \\
\hline Main component of rubber & Natural rubber (NR) & 100 \\
Crosslinking agent & Sulfur fine powder & 3.5 \\
Crosslinking agent & 2-Dibutylamino-4,6-dimercapto-s-triazine & 3 \\
Vulcanisation accelerator & N-(tert-Butyl)-2-benzothiazolesulfenamide (BBS) & 0.7 \\
Vulcanisation accelerator aid & Zinc oxide (ZnO) & 6 \\
Vulcanisation accelerator aid & Stearic acid & 0.5 \\
\hline
\end{tabular}

*Vulcanisation conditions of Sample 4: $150^{\circ} \mathrm{C}$, $8.0 \mathrm{~min}$ 
Table 5. Components of sample 5.

\begin{tabular}{llc}
\hline Role & \multicolumn{1}{c}{ Material } & Amount $[\mathrm{g}]$ \\
\hline Main component of rubber & Natural rubber (NR) & 100 \\
Crosslinking agent & Sulfur fine powder & 3.5 \\
Vulcanisation accelerator & N-(tert-Butyl)-2-benzothiazolesulfenamide (BBS) & 0.7 \\
Vulcanisation accelerator aid & Zinc oxide $(\mathrm{ZnO})$ & 6 \\
Vulcanisation accelerator aid & Stearic acid & 0.5 \\
Reinforcing material & Silica powder $\left(\mathrm{SiO}_{2}\right)$ & 30 \\
\hline
\end{tabular}

*Vulcanisation condition of Sample 5: $180^{\circ} \mathrm{C}, 4.0 \mathrm{~min}$

Table 6. Components of sample 6.

\begin{tabular}{llc}
\hline Role & \multicolumn{1}{c}{ Material } & Amount [g] \\
\hline Main component of rubber & Natural rubber (NR) & 100 \\
Crosslinking agent & Sulfur fine powder & 3.5 \\
Crosslinking agent & 2-Dibutylamino-4,6-dimercapto-s-triazine & 3 \\
Vulcanisation accelerator & N-(tert-Butyl)-2-benzothiazolesulfenamide (BBS) & 0.7 \\
Vulcanisation accelerator aid & Zinc oxide (ZnO) & 6 \\
Vulcanisation accelerator aid & Stearic acid & 0.5 \\
Reinforcing material & Silica powder $\left(\mathrm{SiO}_{2}\right)$ & 30 \\
\hline
\end{tabular}

*Vulcanisation condition of Sample 6: $160^{\circ} \mathrm{C}, 4.0 \mathrm{~min}$

chloroprene rubber (CR, M-40, Denka: Chuo-ku, Tokyo, Japan) and natural rubber (NR, Ribbed Smoked Sheet No. 1, Rubber source: Indonesia) were used as the main rubber components. Cellulose powder (CF11, Whatman: Kent, UK) and hydrophilic $\mathrm{SiO}_{2}$ powder (Nipsil VN3, wet process, Tosoh Silica: Minato-ku, Tokyo, Japan) were used as reinforcing materials. To compare the differences between manufacturing methods, wet and dry processes, hydrophilic $\mathrm{SiO}_{2}$ powder $\left(\mathrm{HDK}^{\oplus} \mathrm{N} 20\right.$, dry process, Wacker Chemie AG: München, Germany), and hydrophobic $\mathrm{SiO}_{2}$ powder covered with polydimethylsiloxane (HDK ${ }^{\odot} \mathrm{H} 18$, dry process, Wacker Chemie AG) were also used as reinforcing agents. Dicumyl peroxide (Percumyl ${ }^{\circledR} \mathrm{D}$, NOF: Shibuya-ku, Tokyo, Japan), fine sulphur powder (325 Mesh, Hosoi Chemical Industry: Chuo-ku, Tokyo, Japan), and 2-dibutylamino-4,6-dimercapto-s-triazine (Zisnet DB, Sankyo Chemical: Osaka, Osaka, Japan) were used as crosslinking agents. Zinc oxide (JIS Grade No.2, Hakusui Tech: Osaka, Osaka, Japan) and stearic acid ( $\mathrm{C}_{16}: 22 \%-32 \%$, Stearic Acid 50S, New Japan Chemical: Osaka, Osaka, Japan) were used as vulcanisation accelerator aids. N-(tert-butyl)-2-benzothiazolesulfenamide (Nocceler NS-P, Ouchi Shinko Chemical Industrial: Chuo-ku, Tokyo, Japan) was used as a vulcanisation accelerator. N-phenyl-1-naphthylamine (Nocrac PA, Ouchi Shinko Chemical Industrial) was used as an antioxidant for rubber. Sample 1 containing CR was prepared to confirm the effect of chloride on adhesion strength. Note that it was assumed that the chlorides would react with peroxide radicals and/or oxygencontaining functional groups on the heat-assisted plasma-treated PTFE. Sample 2 containing NR and dicumyl peroxide was prepared to confirm the effect of a peroxide crosslinking agent on adhesion strength. The dicumyl peroxide induces the generation of carbon radicals in NR by changing double bonds to single 
bonds. It was assumed that the carbon radicals would react with peroxide radicals and/or oxygen-containing functional groups on the heat-assisted plasma-treated PTFE. Sample 3 containing NR and sulphur was prepared to confirm the effect of a sulphur crosslinking agent on adhesion strength. It was assumed that sulphur would react with peroxide radicals and/or oxygen-containing functional groups on the heat-assisted plasma-treated PTFE. Sample 4 containing NR, sulphur, and triazine thiol was prepared to confirm the effect of a thiol crosslinking agent on adhesion strength. It was assumed that the triazine thiols would react with peroxide radicals and/or oxygen-containing functional groups on the heatassisted plasma-treated PTFE. Sample 5 containing NR, sulphur, and $\mathrm{SiO}_{2}$ powder was prepared to confirm the effect of $\mathrm{SiO}_{2}$ powder on adhesion strength. It was assumed that the $\mathrm{SiO}_{2}$ powder would react with peroxide radicals and/or oxygen-containing functional groups on the heat-assisted plasma-treated PTFE. Sample 6 containing NR, sulphur, triazine thiol, and $\mathrm{SiO}_{2}$ powder was prepared to confirm the effect of both triazine thiol and $\mathrm{SiO}_{2}$ powder on adhesion strength.

\section{Method}

\section{Plasma treatment}

Prior to use, PTFE sheets were sequentially washed with acetone (99.5\%, Kishida Chemical: Osaka, Osaka, Japan) and pure water for $1 \mathrm{~min}$ each using an ultrasonic bath (USK-1R, AS-ONE: Osaka, Osaka, Japan). The washed PTFE sheets were then dried using an air gun containing $\mathrm{N}_{2}$ gas (99.99\%, Iwatani Fine Gas: Amagasaki, Hyogo, Japan). The dried PTFE sheets were then fixed on a cylindrical rotation stage $(\mathrm{L}=34 \mathrm{~mm}, \Phi=40 \mathrm{~mm}) .{ }^{[15]}$ The stage containing PTFE sample was placed in a custom-made chamber (Meisyo

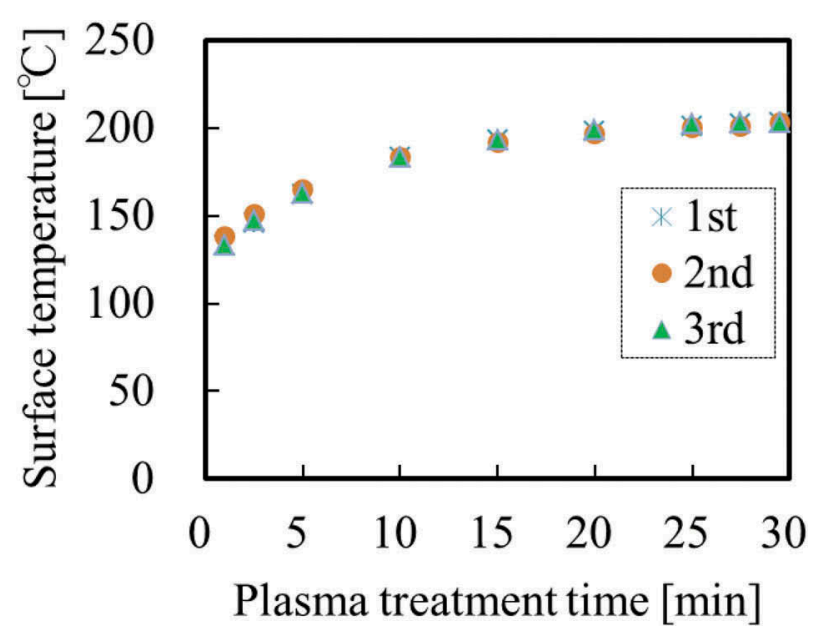

Figure 1. Representative temperature profiles of PTFE surface during heat-assisted plasma treatment for $600 \mathrm{~s}$ at $18.7 \mathrm{~W} / \mathrm{cm}^{2}$ three times. 
Kiko: Tanba, Hyogo, Japan) with the vacuum system. ${ }^{[20]}$ The reactor pressure was decreased to below 10 Pa using a rotary pump (GDH-361, Shimadzu: Kyoto, Kyoto, Japan) then helium gas (He, 99.99\%, Iwatani Fine Gas) was introduced until the atmospheric pressure (101300 Pa). Plasma was generated between two electrodes using a $13.56 \mathrm{MHz}$ radio frequency $(\mathrm{RF})$ generator in the camber filled with He gas without flowing. All the PTFE sheets were heatassisted plasma-treated for $600 \mathrm{~s}$ at $18.7 \mathrm{~W} / \mathrm{cm}^{2}$. The surface temperature of the PTFE samples during plasma treatment was measured with a digital radiation thermometer system (FT-H40K and FT-50A, Keyence: Osaka, Osaka, Japan). Figure 1 shows the representative temperature profiles of PTFE surface three times. It was confirmed that all the maximum surface temperatures were above $200^{\circ} \mathrm{C}$. All the error of temperature profiles three times were within $5^{\circ} \mathrm{C}$, which indicates high reproducibility. Effect of surface temperature on adhesion strength of PTFE were previously studied and reported. ${ }^{[14,15]}$ When surface temperature of PTFE during plasma treatment was lower than $100^{\circ} \mathrm{C}$, the adhesion strength of plasma-treated PTFE/IIR was below $0.2 \mathrm{~N} / \mathrm{mm}$. In contrast, when surface temperature of PTFE during plasma treatment was higher than $200^{\circ} \mathrm{C}$, the adhesion strength of plasma-treated PTFE/IIR was above $2.0 \mathrm{~N} / \mathrm{mm}$ and cohesion failure of IIR occurred. According to these reports, plasma condition (for $600 \mathrm{~s}$ at $18.7 \mathrm{~W} / \mathrm{cm}^{2}$ ) in this study was chosen to be at higher than $200^{\circ} \mathrm{C}$.

Prior to adhesion strength test, confirmation of surface chemical composition using a Quantum 2000 instrument (Ulvac-Phi: Chigasaki, Kanagawa, Japan), confirmation of generation of peroxide radicals $\left(\mathrm{C}-\mathrm{O}-\mathrm{O}^{*}\right)$ using a JES-FA100x (JEOL: Akishima, Tokyo, Japan), and adhesion confirmation test of heat-assisted plasma-treated PTFE for $600 \mathrm{~s}$ at $18.7 \mathrm{~W} / \mathrm{cm}^{2}$ were performed. Although only the peak attributed to $\mathrm{CF}_{2}$ was observed at ca. $292 \mathrm{eV}$ for as-received PTFE in Figure 2, the intensity of the peak attributed to fluorine-containing functional groups $\left(\mathrm{CF}_{3}, \mathrm{CF}_{2}, \mathrm{C}-\mathrm{F}\right)$ decreased and the intensities of the peaks attributed to oxygen-containing functional groups
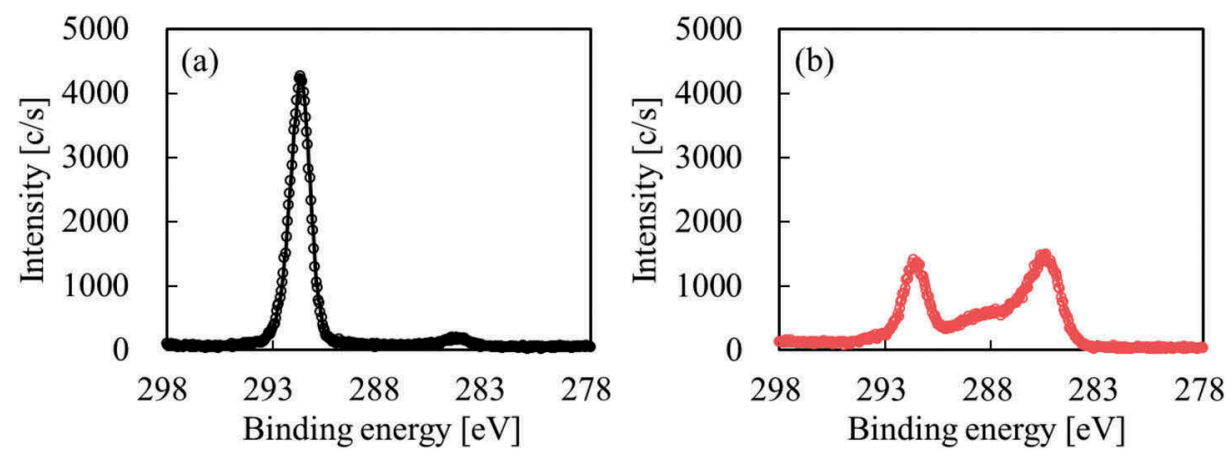

Figure 2. Representative C1s-XPS spectra of PTFE samples (a) before and (b) after heat-assisted plasma treatment for $600 \mathrm{~s}$ at $18.7 \mathrm{~W} / \mathrm{cm}^{2}$. 

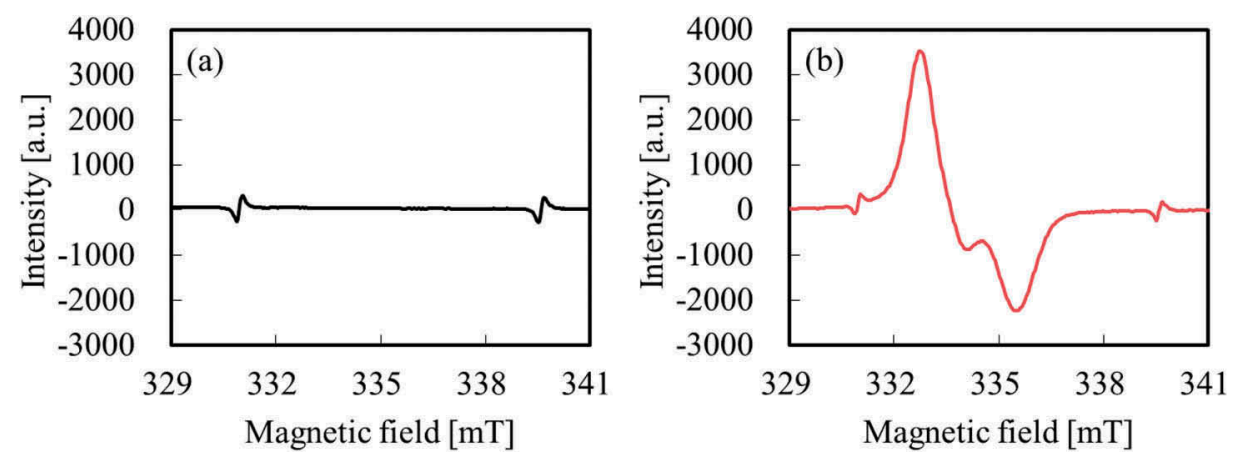

Figure 3. Representative ESR spectra of PTFE samples (a) before and (b) after heat-assisted plasma treatment for $600 \mathrm{~s}$ at $18.7 \mathrm{~W} / \mathrm{cm}^{2}$.

(1) Ultrasonic washing

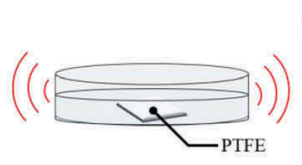

(2) Plasma treatment

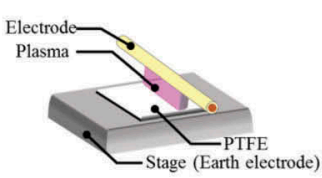

(3) Thermal compression

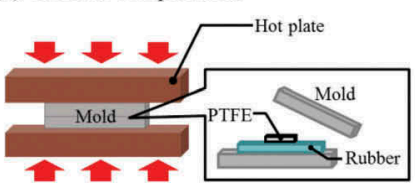

(4) T-peel test

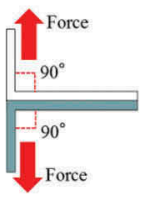

Figure 4. Schematic diagram of the sample preparation sequence for the adhesion test.

$(\mathrm{O}-\mathrm{C}=\mathrm{O}, \mathrm{C}=\mathrm{O}, \mathrm{C}-\mathrm{O})$ and carbon groups $(\mathrm{C}-\mathrm{C}, \mathrm{C}=\mathrm{C})$ increased in Figure 2 as compared to those of the as-received PTFE upon heat-assisted plasma treatment. Although only the peaks attributed to $\mathrm{Mn}^{2+}$ markers were observed at ca. 331 and $340 \mathrm{mT}$ for as-received PTFE in Figure 3, the peak attributed to alkyl-type peroxide radicals $\left(-\mathrm{CF}_{2} \mathrm{CFOO}^{\circ} \mathrm{CF}_{2}-\right)$ was detected upon heat-assisted plasma treatment in Figure 3. These behavior in this study were consistent with those in previous reports. ${ }^{[1,15]}$ It is previously reported that oxygen-containing functional groups and peroxy radicals generate when fluoropolymers plasma-treated using noble gas is exposed to the air. ${ }^{[21]}$ In addition, the plasma-treated PTFE/IIR was also above $2.0 \mathrm{~N} / \mathrm{mm}$ and cohesion failure of IIR also occurred. As a result, it was confirmed that this plasma condition had no problems. Plasma treatment was performed only on the PTFE surface and not on the unvulcanised rubber surface.

\section{Adhesion strength test}

Figure 4 shows a schematic diagram of the general sequence for the adhesion test. First, the plasma-treated PTFE samples were placed on unvulcanised rubber sheets in a mould. Second, the assembly samples were compressed at appropriate temperatures and times for each type of unvulcanised rubber because of complete crosslinking occurring when using a hot-pressing machine (AH-2003, AS-ONE). Each vulcanisation time was confirmed via 

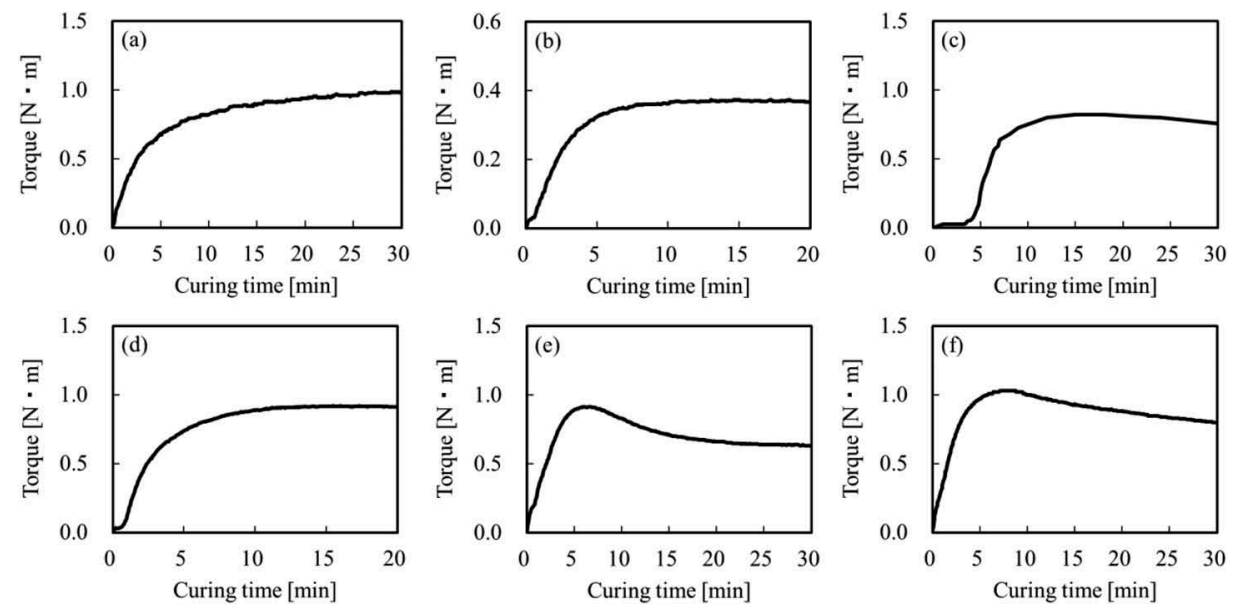

Figure 5. Results of the vulcanisation judgement test for confirmation of proper vulcanisation time. (a) Sample 1 at $180^{\circ} \mathrm{C}$, (b) sample 2 at $170^{\circ} \mathrm{C}$, (c) Sample 3 at $160^{\circ} \mathrm{C}$, (d) Sample 4 at $150^{\circ} \mathrm{C}$, (e) Sample 5 at $180^{\circ} \mathrm{C}$, and (f) Sample 6 at $160^{\circ} \mathrm{C}$.

a vulcanisation judgement test using a rubber testing machine (Curelastometer type V, Orientec: Toyoshima-ku, Tokyo, Japan), as shown in Figure 5. Here no adhesives were used in the adhesion process. Third, the rubber/PTFE assembly was returned to room temperature. Fourth, the adhesion strengths of the rubber/PTFE assembly was measured with a T-peel test using a universal testing device (AG-1000D, Shimadzu) and/or combination of a digital force gauge (ZP-200N, Imada; Toyohashi, Aichi, Japan) and an electric-driven stand (MX-500N, Imada). Finally, the adhesion strengths were calculated by dividing the average tensile strength by the width of the rubber/ PTFE assembly (ca. $10 \mathrm{~mm}$ ). Three samples were prepared under the same conditions to confirm the reproducibility.

\section{Surface chemical composition analysis}

XPS measurements were conducted with a scanning XPS microprobe (PHI5000VersaProbeII, Ulvac-Phi) attached to a monochromated Al-Ka source. The XPS spectra were obtained at a take-off angle of $45^{\circ}$. The area of X-ray irradiation was $\Phi=100 \mu \mathrm{m}$, the pass energy was $11.75 \mathrm{eV}$, and the step size was $0.05 \mathrm{eV}$. C1s-XPS and Si2p-XPS spectra were collected from 280 to $296 \mathrm{eV}$ and from 95 to $110 \mathrm{eV}$, respectively. The cumulative number of the measurements was five. During a XPS measurement, the low-speed electron beam and an Ar ion beam were used to irradiate the measured samples to neutralise their charges. 


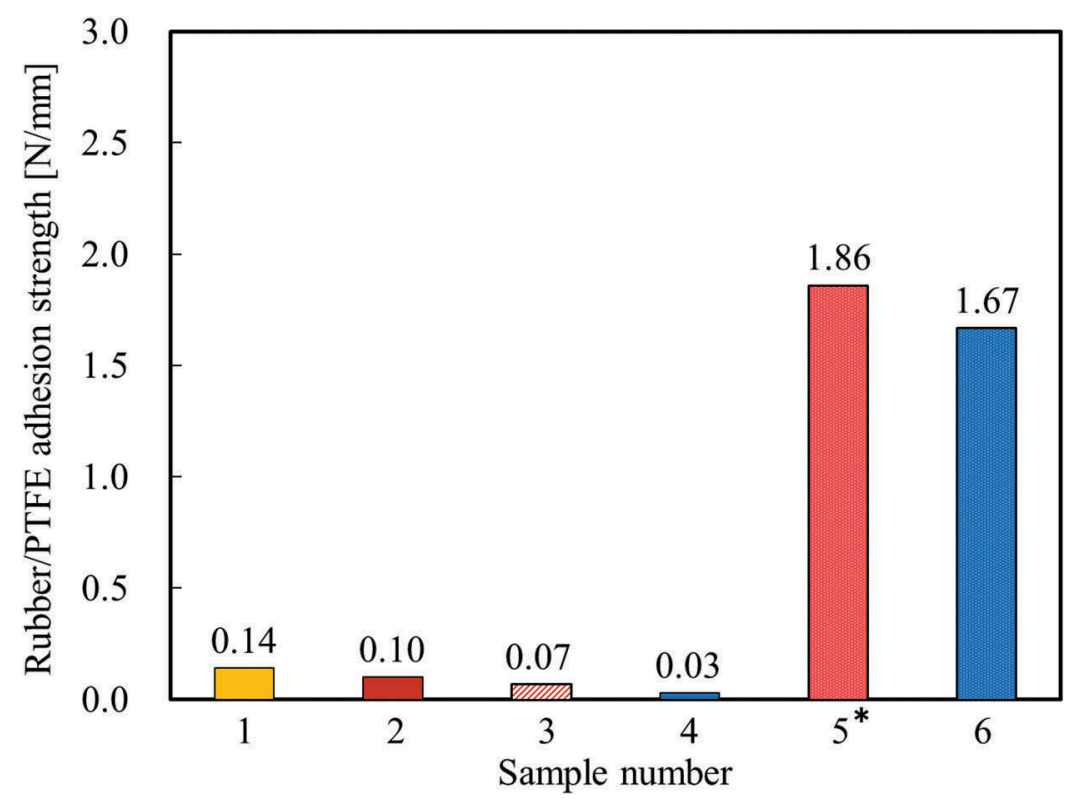

Figure 6. Adhesion strength between the heat-assisted plasma-treated PTFE and rubber for samples 1-6 prepared as shown in Table 1-6. no adhesives were used. * indicates that cohesion failure of rubber occurred in the middle of a T-peel test.
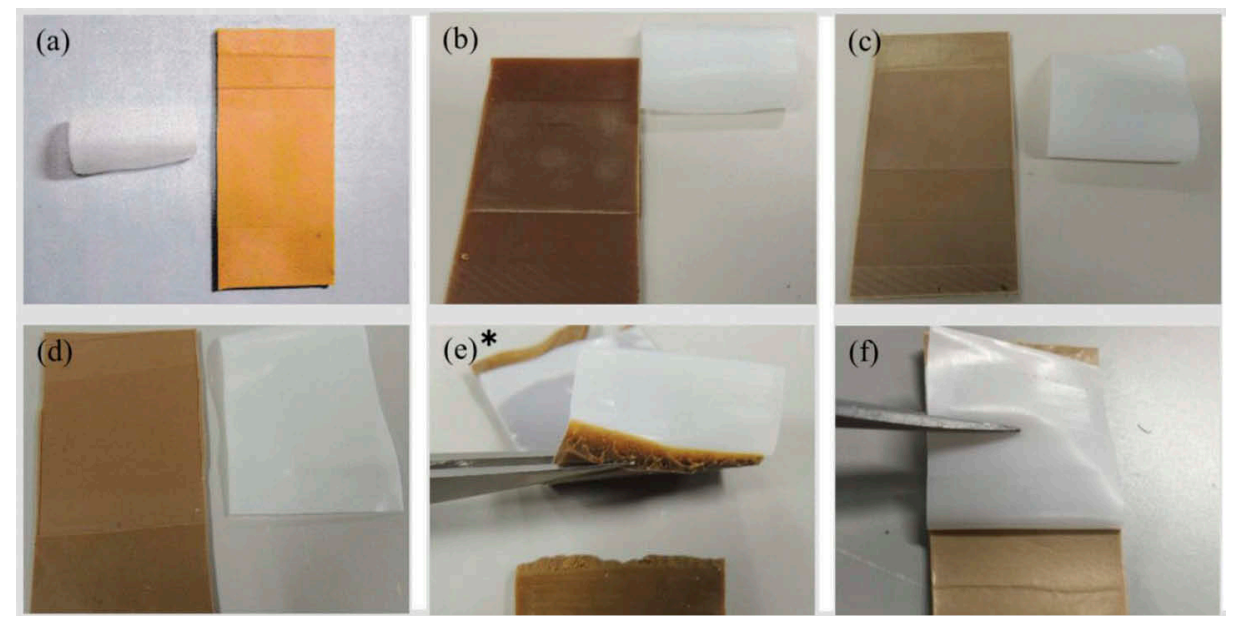

Figure 7. Photographs of samples 1-6 after T-peel test. (a) sample 1, (b) sample 2, (c) sample 3, (d) sample 4, (e) sample 5, and (f) sample $6 .{ }^{*}$ indicates that cohesion failure of rubber occurred in the middle of a T-peel test.

\section{Results and discussion}

\section{Adhesion strength between plasma-treated PTFE and rubber}

Figure 6 shows the adhesion strength between plasma-treated PTFE and rubber Samples 1-6. Figure 7 shows the photographs of Samples 1-6 after 
the T-peel test. For Sample 1, the adhesion strength was $0.14 \mathrm{~N} / \mathrm{mm}$ and the rubber was easily peeled (Figure 7a). This indicates that chlorides do not interact with peroxide radicals and/or oxygen-containing functional groups on heat-assisted plasma-treated PTFE. For Sample 2, the adhesion strength was $0.10 \mathrm{~N} / \mathrm{mm}$ and the rubber was easily peeled (Figure $7 \mathrm{~b}$ ). This indicates that carbon radicals do not interact with peroxide radicals and/or oxygen-containing functional groups on heat-assisted plasma-treated PTFE. For Sample 3, the adhesion strength was $0.07 \mathrm{~N} / \mathrm{mm}$ and the rubber was easily peeled (Figure $7 \mathrm{c}$ ). This indicates that the sulphur does not interact with peroxide radicals and/or oxygen-containing functional groups on the heat-assisted plasma-treated PTFE. For Sample 4, the adhesion strength was $0.03 \mathrm{~N} / \mathrm{mm}$ and the rubber was also easily peeled (Figure $7 \mathrm{~d}$ ). This indicates that triazine thiols do not interact with peroxide radicals and/or oxygen-containing functional groups on heatassisted plasma-treated PTFE. For Sample 5, the adhesion strength was $1.86 \mathrm{~N} / \mathrm{mm}$ and cohesion failure of rubber occurred (Figure 7e). This indicates that $\mathrm{SiO}_{2}$ powder interacts with peroxide radicals and/or oxygen-containing functional groups on heat-assisted plasma-treated PTFE. For Sample 6, the adhesion strength was $1.67 \mathrm{~N} / \mathrm{mm}$ and the rubber was difficult to peel but cohesion failure of rubber did not occur (Figure $7 \mathrm{f}$ ). The adhesion strength of Sample $6(1.67 \mathrm{~N} / \mathrm{mm})$ was much higher than that of Sample $4(0.04 \mathrm{~N} / \mathrm{mm})$ but slightly lower than that of Sample 5 $(1.86 \mathrm{~N} / \mathrm{mm})$. These results indicate that the $\mathrm{SiO}_{2}$ powders positively affect the adhesion strength, but the triazine thiols negatively affect the adhesion strength.

To confirm the additive effect of $\mathrm{SiO}_{2}$ powder on the adhesion strength, NR samples were prepared with different amounts of added $\mathrm{SiO}_{2}$ in the range 0-40 g to $100 \mathrm{~g}$ NR. This component is shown in Table 7. Except for $\mathrm{SiO}_{2}$, other components and their amounts for Table 7 are the same as in Sample 5 (Table 5). Figure 8 shows the adhesion strength between the heat-assisted plasma-treated PTFE and NR samples prepared with different amounts of $\mathrm{SiO}_{2}$. The adhesion strength increased with increasing the amount of $\mathrm{SiO}_{2}$ and cohesion failure of NR occurred when 30 and $40 \mathrm{~g} \mathrm{SiO}_{2}$ were added. It is confirmed that the addition of $\mathrm{SiO}_{2}$ powder to $\mathrm{NR}$ affected the adhesion strength.

Table 7. Components of NR with different amounts of $\mathrm{SiO}_{2}$.

\begin{tabular}{llc}
\hline Role & \multicolumn{1}{c}{ Material } & Amount [g] \\
\hline Main component of rubber & Natural rubber (NR) & 100 \\
Crosslinking agent & Sulfur fine powder & 3.5 \\
Vulcanisation accelerator & $N$-(tert-Butyl)-2-benzothiazolesulfenamide (BBS) & 0.7 \\
Vulcanisation accelerator aid & Zinc oxide (ZnO) & 6 \\
Vulcanisation accelerator aid & Stearic acid & 0.5 \\
Reinforcing material & Silica powder $\left(\mathrm{SiO}_{2}\right)$ & $0,10,20,30,40$ \\
\hline
\end{tabular}




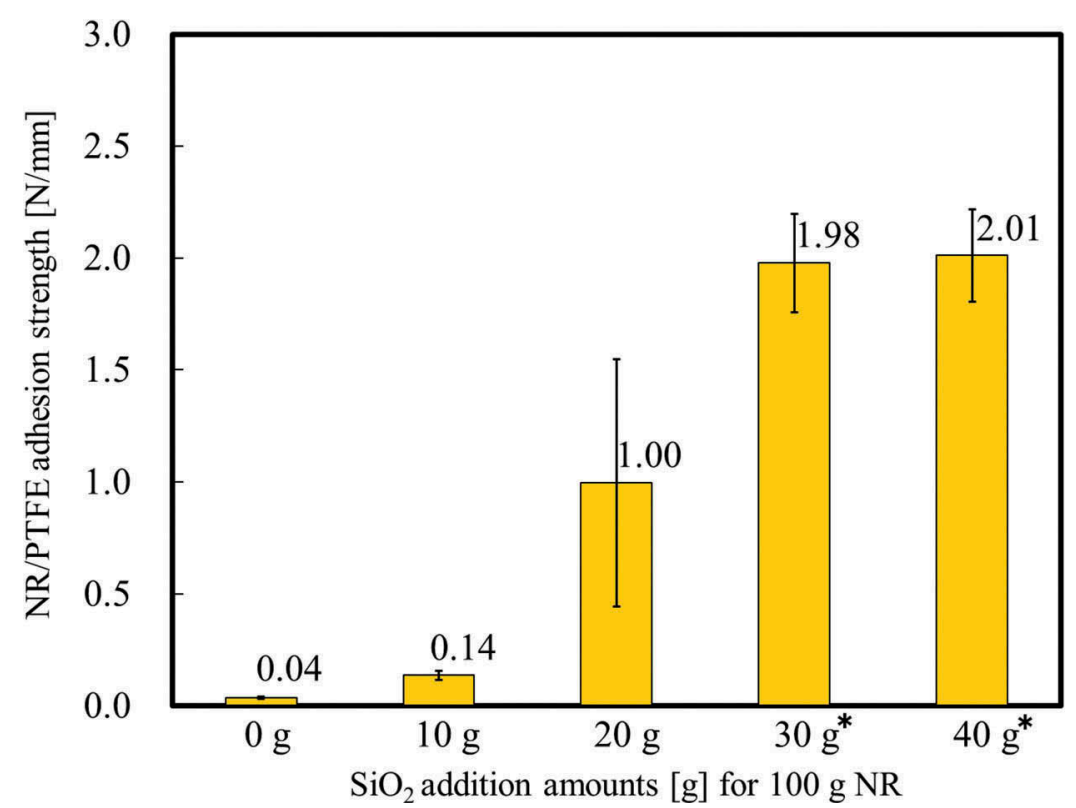

Figure 8. Adhesion strength between the heat-assisted plasma-treated PTFE and NR samples prepared with different amounts of $\mathrm{SiO}_{2}$ as shown in Table 7. ${ }^{*}$ indicates that cohesion failure of rubber occurred in the middle of a T-peel test.

\section{Confirmation of reaction between plasma-treated PTFE and $\mathrm{SiO}_{2}$ powder using XPS}

To confirm the reaction between plasma-treated PTFE and $\mathrm{SiO}_{2}$ powder, a direct reaction was observed in the absence of all the NR components except for $\mathrm{SiO}_{2}$ powder. First, $\mathrm{SiO}_{2}$ powder was directly thermally compressed to heat-assisted plasma-treated PTFE sheet at almost $10 \mathrm{MPa}$ at $180^{\circ} \mathrm{C}$ for $10 \mathrm{~min}$ using a compression moulding machine (NF-50, Shinto Metal Industries), as shown in Figure 9a. Second, the unreacted $\mathrm{SiO}_{2}$ powder on the plasma-treated PTFE was removed by washing with tap water for ca. $20 \mathrm{~s}$ and with distilled water for ca. $10 \mathrm{~s}$, followed by ultrasonic washing in distilled water for $5 \mathrm{~min}$; each wash was repeated more than four times (Figure 9b). Finally, XPS measurements were conducted. Prior to the XPS measurements, all the samples were dried using an air gun. For comparison, a reference sample was prepared using as-received PTFE via the process shown in Figure 9.

Figure 10 shows the XPS spectra of the PTFE surface after thermal compression with $\mathrm{SiO}_{2}$ powder (VN3). Although only the peak attributed to $\mathrm{CF}_{2}$ was observed at $\mathrm{ca} .292 \mathrm{eV}$ for as-received PTFE, the intensity of the peak attributed to fluorine-containing functional groups $\left(\mathrm{CF}_{3}, \mathrm{CF}_{2}\right.$, $\mathrm{C}-\mathrm{F}$ ) decreased and the intensities of the peaks attributed to oxygencontaining functional groups $(\mathrm{O}-\mathrm{C}=\mathrm{O}, \mathrm{C}=\mathrm{O}, \mathrm{C}-\mathrm{O})$ and main carbon groups $(\mathrm{C}-\mathrm{C}, \mathrm{C}-\mathrm{H}, \mathrm{C}=\mathrm{C})$ increased as compared to those of the 


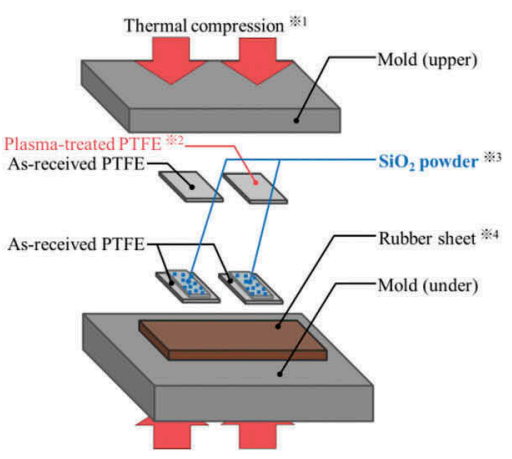

(a)

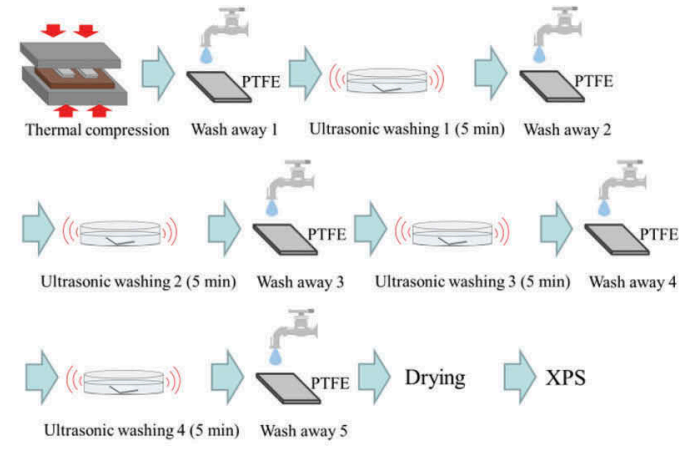

(b)

Figure 9. Schematic diagram of the sequence for confirming the reaction between plasmatreated PTFE and $\mathrm{SiO}_{2}$ powder using XPS. (a) before thermal compression, (b) after thermal compression. ${ }^{* 1}$ Thermal compression was performed at almost $10 \mathrm{MPa}$ at $180^{\circ} \mathrm{C}$ for $10 \mathrm{~min} .{ }^{* 2}$ Heat-assisted plasma treatment was performed for $600 \mathrm{~s}$ at $18.7 \mathrm{~W} / \mathrm{cm}^{2} .{ }^{*}$ Three types of $\mathrm{SiO}_{2}$ powders: VN3, H18, and N20 were used. ${ }^{* 4} \mathrm{~A}$ vulcanised rubber having high heat-resistance was used as a cushion.
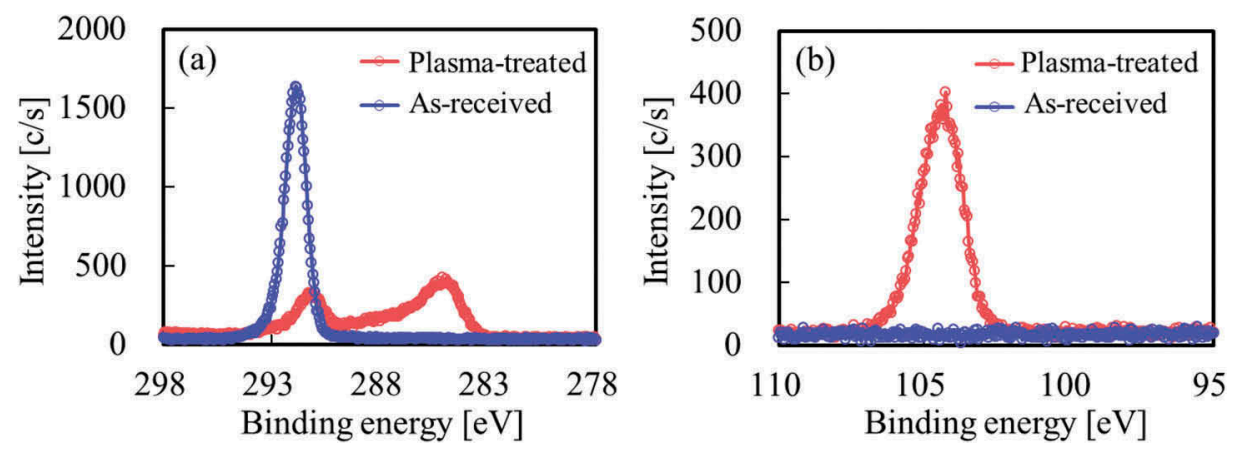

Figure 10. XPS spectra of the PTFE surface after thermal-compression with hydrophilic $\mathrm{SiO}_{2}$ powder (VN3) (a) C1s, (b) Si2p.

as-received PTFE upon heat-assisted plasma treatment, as shown in the C1s-XPS spectra (Figure 10a). As a result, surface modification of PTFE via heat-assisted plasma treatment was confirmed. Si was detected on the plasma-treated PTFE but not the as-received PTFE by Si2p-XPS spectrum (Figure 10b). These results indicated that $\mathrm{SiO}_{2}$ powder remained on the plasma-treated PTFE surface despite repeated washing. In addition, the strong adhesion of $\mathrm{SiO}_{2}$ powder implied that this chemically reacted with the plasma-treated PTFE surface.

To compare the effect of wettability of $\mathrm{SiO}_{2}$ surface on adhesion to PTFE, hydrophobic $\mathrm{SiO}_{2}$ powder (H18), which was prepared through a dry process, was used for the same confirmation test. Figure 11 shows the XPS spectra of the PTFE surface after thermal compression with hydrophobic $\mathrm{SiO}_{2}$ powder 

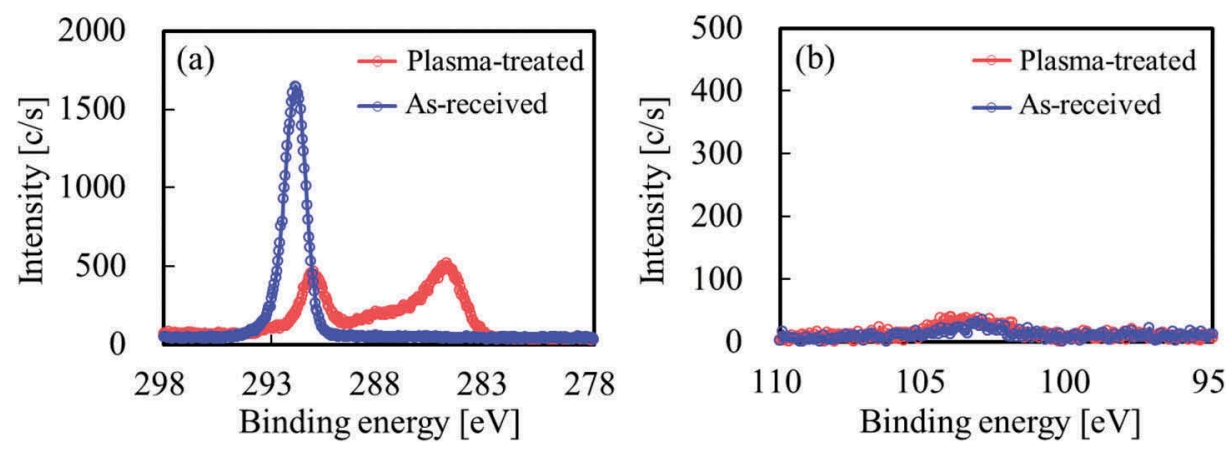

Figure 11. XPS spectra of the PTFE surface after thermal-compression with hydrophobic $\mathrm{SiO}_{2}$ powder (H18) (a) C1s, (b) Si2p.

(H18). Figure 11a as well as Figure 10a indicates surface modification of PTFE via heat-assisted plasma treatment. In contrast, Si was barely detected in either the as-received or the plasma-treated PTFE via Si2p-XPS spectra (Figure 11b). These results indicated that hydrophobic $\mathrm{SiO}_{2}$ powder barely remained on the plasma-treated PTFE surface as there was no interaction between both materials.

VN3 is a hydrophilic $\mathrm{SiO}_{2}$ powder prepared through a wet process, whereas $\mathrm{H} 18$ is a hydrophobic $\mathrm{SiO}_{2}$ powder prepared through a dry process. Taking the manufacturing method of $\mathrm{SiO}_{2}$ powder into account, hydrophilic $\mathrm{SiO}_{2}$ powder (N20), which was prepared through a dry process, was used for the same confirmation test. Figure 12 shows the XPS spectra of the PTFE surface after thermal compression with hydrophilic $\mathrm{SiO}_{2}$ powder (N20). Figure 12a as well as Figures 10a and 11a indicates surface modification of PTFE via heat-assisted plasma treatment. Si was detected in the plasmatreated PTFE but not the as-received PTFE via the Si2p-XPS spectra in Figure $12 \mathrm{~b}$ as well as Figure $10 \mathrm{~b}$.
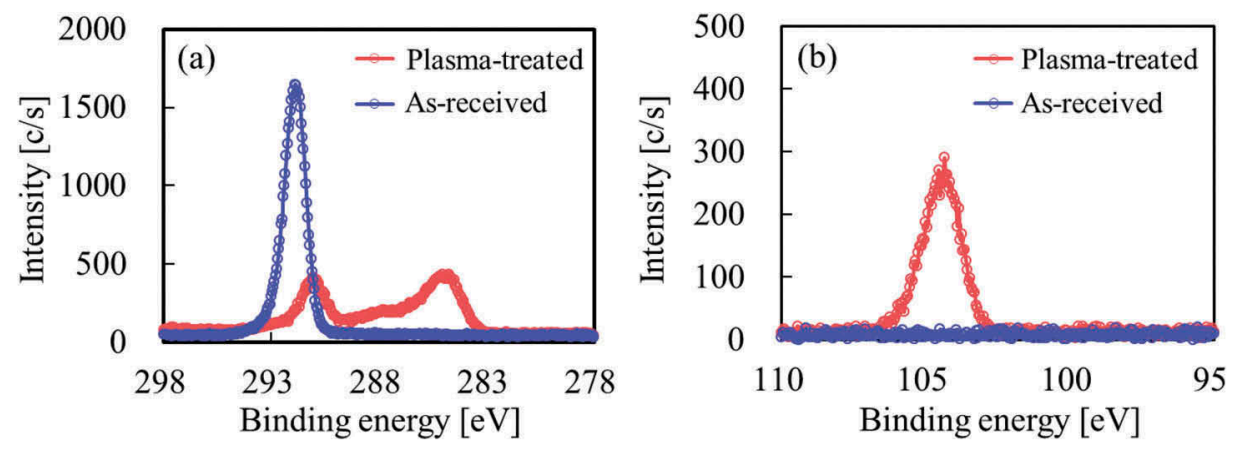

Figure 12. XPS spectra of the PTFE surface after thermal-compression with hydrophilic $\mathrm{SiO}_{2}$ powder (N20) (a) C1s, (b) Si2p. 
Table 8. Atomic ratios of the PTFE surface after thermal compression with $\mathrm{SiO}_{2}$ powder, which calculated from each survey XPS spectrum.

\begin{tabular}{lcrcc}
\hline Sample condition & C1s & 01s & F1s & Si2p \\
\hline VN3/PTFE(as-received) & 30.3 & 0.2 & 69.6 & 0.0 \\
VN3/PTFE(plasma-treated) & 34.5 & 33.6 & 22.4 & 9.5 \\
H18/PTFE(as-received) & 29.2 & 0.8 & 69.8 & 0.2 \\
H18/PTFE(plasma-treated) & 54.5 & 10.2 & 34.6 & 0.8 \\
N20/PTFE(as-received) & 31.2 & 0.2 & 68.6 & 0.0 \\
N20/PTFE(plasma-treated) & 36.6 & 18.6 & 40.2 & 4.6 \\
\hline
\end{tabular}

The atomic ratios of the PTFE surface after thermal compression with $\mathrm{SiO}_{2}$ powder were calculated from the survey XPS spectra, as shown in Table 8. For all as-received PTFE, the Si atomic ratios were lower than $1 \%$. In contrast, for plasma-treated PTFE except addition of hydrophobic $\mathrm{SiO}_{2}(\mathrm{H} 18)$, the $\mathrm{Si}$ atomic ratios were higher than $4.5 \%$. Although two types of hydrophilic $\mathrm{SiO}_{2}$ powder (VN3 and N20) strongly adhered to the plasma-treated PTFE surface, hydrophobic $\mathrm{SiO}_{2}$ powder $(\mathrm{H} 18)$ did not adhere. The difference indicates that silanol groups $(\mathrm{Si}-\mathrm{OH})$ of the $\mathrm{SiO}_{2}$ surface affect the adhesion strength between the plasma-treated PTFE and rubber. A proposed model for strong adhesion is shown in Figure 13. First, peroxy radicals and oxygen-containing functional groups $(\mathrm{C}(=\mathrm{O})$ $\mathrm{OH}, \mathrm{C}-\mathrm{OH})$ are generated upon plasma treatment. Second, peroxy radicals on the plasma-treated PTFE may induce the dehydrogenation of rubber. Third, hydroxyl and carboxyl groups are generated regardless of the presence or absence of the second step: dehydrogenation of rubber. Fourth, hydrogen bonds are formed between hydroxyl and carboxyl

(1) Generation of peroxy radicals and oxygen-containing functional groups

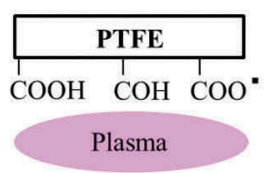

(4) Formation of hydrogen bond between hydroxyl and carboxyl groups

\begin{tabular}{|c|c|c|}
\hline \multicolumn{3}{|c|}{ PTFE } \\
\hline $\mathrm{COOH}$ & $\mathrm{COH}$ & $\mathrm{COOH}$ \\
\hline $\mathrm{HO}$ & HO & $\mathrm{OH}$ \\
\hline $\begin{array}{lll}0 & 0 & 1 \\
0 & 0 & 5 \\
\end{array}$ & ${ }_{0}^{\circ} \mathrm{Si}_{\mathrm{i}}$ & So \\
\hline
\end{tabular}

(2) Dehydrogenation of rubber via radicals

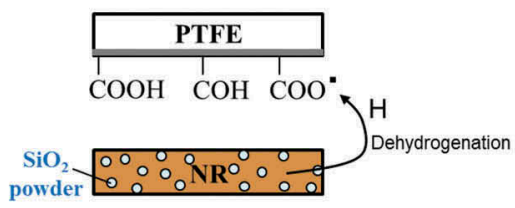

(5) Dehydration condensation between silanol and hydroxyl or carboxyl groups

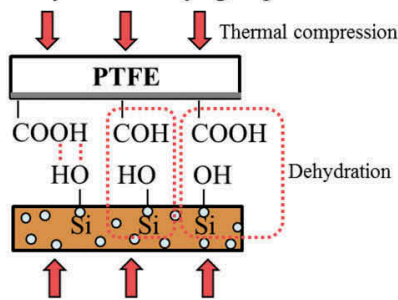

(3) Formation of hydroxyl and carboxyl groups

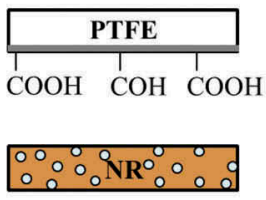

(6) Formation of $\mathrm{C}(=\mathrm{O})-\mathrm{O}-\mathrm{Si}$ and/or C-O-Si bonds

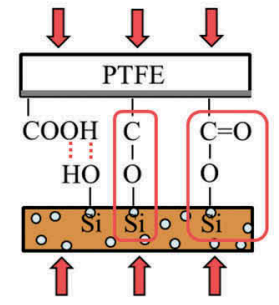

Figure 13. Proposed model for strong adhesion between heat-assisted plasma-treated PTFE and rubber containing $\mathrm{SiO}_{2}$ powder. 
groups on the PTFE surface and silanol groups of the $\mathrm{SiO}_{2}$ powder on the rubber surface. Fifth, dehydration condensation occurs between silanol and hydroxyl or carboxyl groups. Finally, $\mathrm{C}-\mathrm{O}-\mathrm{Si}$ and/or $\mathrm{C}(=\mathrm{O})-\mathrm{O}-\mathrm{Si}$ bonds are formed. Considering that NR cohesion failure occurred when $\mathrm{SiO}_{2}$ powder was added, it is reasonable to suppose that covalent bonds as well as hydrogen bonds are formed.

\section{Conclusion}

We prepared six types of rubbers to clarify the effects of rubber compounding agent on adhesion strength between rubber and heat-assisted plasmatreated PTFE. It was found that addition of $\mathrm{SiO}_{2}$ powder to rubber was particularly effective for improving the adhesion strength. The adhesion strength increased with increasing the amount of $\mathrm{SiO}_{2}$, and the cohesion failure of rubber occurred when the amount of $\mathrm{SiO}_{2}$ was more than $30 \mathrm{~g}$ to $100 \mathrm{~g}$ NR. In addition, it was confirmed that hydrophilic $\mathrm{SiO}_{2}$ powder strongly adhered to the heat-assisted plasma-treated PTFE surface. We proposed a model of high adhesion strength upon addition of $\mathrm{SiO}_{2}$ powder. This simple method of adding $\mathrm{SiO}_{2}$ powder could be applied not only to rubber but also to various polymers to improve their adhesion to heat-assisted plasma-treated fluoropolymers.

\section{Acknowledgments}

The study was supported by a grant from the Japan Society for the Promotion of Science (JSPS KAKENHI Grant Number 15K05723).

\section{Funding}

This work was supported by the Japan Society for the Promotion of Science [JSPS KAKENHI Grant Number 15K05723].

\section{ORCID}

Yuji Ohkubo (iD http://orcid.org/0000-0001-7366-5108

\section{References}

[1] Schonhorn, H.; Hansen, R. H. J. Appl. Polym. Sci. 1967, 11, 1461-1474.

[2] Bikerman, J. J.;. Ind. Eng. Chem. 1967, 59, 40-44.

[3] Marchesi, J. T.; Keith, H. D.; Garton, A. J. Adhesion. 1992, 39, 185-205.

[4] Okubo, M.; Tahara, M.; Aburatani, Y.; Kuroki, T.; Hibino, T. IEEE Trans. Ind. Appl. 2010, 46, 1715-1721. 
[5] Inagaki, N.; Tasaka, S.; Umehara. J. Appl. Polym. Sci. 1999, 71, 2191-2200.

[6] Kim, S. R.;. J. Appl. Polym. Sci. 2000, 77, 1913-1920.

[7] Seo, Y.; Kim, S.; Kim, H.; Kim, J. Langmuir. 2005, 21, 3432-3435.

[8] Rodriguez-Santiago, V.; Bujanda, A. A.; Stein, B. E.; Pappas, D. D. Plasma Process. Polym. 2011, 8, 631-639.

[9] Watanabe, T.; Iwao, T.; Yumoto, M. IEEJ Trans. Fund. Mater. 2012, 132, 245-250.

[10] Kang, E. T.; Zhang, Y. Adv. Mater. 2000, 12, 139-150.

[11] Zhang, M. C.; Kang, E. T.; Neoh, K. G.; Tan, K. L. Colloid. Surf. A. 2001, 176, 139-150.

[12] Zhang, L.; Chen, Y.; Dong, T. Surf. Interface Anal. 2004, 36, 311-316.

[13] Takata, R.; Nagasaka, Y.; Li, Q.; Iwao, T.; Yumoto, M. IEEJ Trans. Fund. Mater. 2015, $135,41-46$.

[14] Ohkubo, Y.; Ishihara, K.; Sato, H.; Shibahara, M.; Nagatani, A.; Honda, K.; Endo, K.; Yamamura, K. RSC Adv. 2017, 7, 6432-6438.

[15] Ohkubo, Y.; Ishihara, K.; Shibahara, M.; Nagatani, A.; Honda, K.; Endo, K.; Yamamura, K. Sci. Rep. 2017, 7, 9476.

[16] Tsai, Y. M.; Boerio, F. J.; Kim, D. K. J. Adhesion. 1997, 61, 247-270.

[17] Cho, P. L.; Jeon, G. S.; Ryu, S. K.; Seo, G. J. Adhesion. 1999, 70, 241-258.

[18] Jeon, G. S.; Han, M. H.; Seo, G. J. Adhesion Sci. Technol. 1999, 13, 153-168.

[19] Jayaseelan, S. K.; Van Ooij, W. J. J. Adhesion Sci. Technol. 2001, 15, 967-991.

[20] Yamamoto, Y.; Akiyama, H.; Ooka, K.; Yamamura, K.; Oshikane, Y.; Zettsu, N. Curr. Appl. Phys. 2012, 12, S63-S68.

[21] Momose, Y.; Tamura, Y.; Ogino, M.; Okazaki, S.; Hirayama, M. J. Vac Sci. Technol. A. 1992, 10, 229-238. 